\title{
INFLUENCE OF ACCELERATION ON THE CMMS ACCURACY IN FAST \\ MEASURING
}

\author{
Thai Thi Thu Ha, Pham Hong Thanh \\ University of Technology, VNU-HCM \\ (Manuscript Received on April $5^{\text {th }}$, 2012, Manuscript Revised November 20 ${ }^{\text {rd }}$, 2012)
}

ABSTRACT: This paper presents a theoretic and practical approach to confirm the dynamic errors induced by acceleration on CMMs during fast measuring. To simplify, a physical model, a mathematical model of the bridge component and the prismatic joint that move along $X$ axis of a bridge CMM are presented. The research points out that there is sure to be the dynamic errors when there is acceleration. This has been demonstrated by the simulation of the errors on the tip probe by Matlab sofware and the experimental results are obtained. The dynamic errors will decrease the accuracy of CMMs so it is necessary to make out a compensation software to keep up the the accuracy of the measuring results.

Keywords: Fast measuring, Fast probing, CMMs, Accuracy, Velocity, Acceleration, Dynamic error...

\section{INTRODUCTION}

Today, CMMs have been developed in the trend that they're kept up their accuracy during fast measuring [2], [4], [12]. When CMMs are measuring at high speed, there are some kinetic elements, which cause the dynamic errors and reduce the accuracy of CMMs. They are the approach distance to the surface, the speed of the approach to the surface, $t /$ he acceleration of the approach to the surface and the direction of the approach to the surface [5]. Therefore, it is necessary to research the influence of these kinetic elements on the accuracy of CMMs and suggest some methods or some directions of solution to make sure the demand CMM's accuracy in fast probing.

\section{STRUCTURE OF THE MOVING BRIDGE CMM [14]}

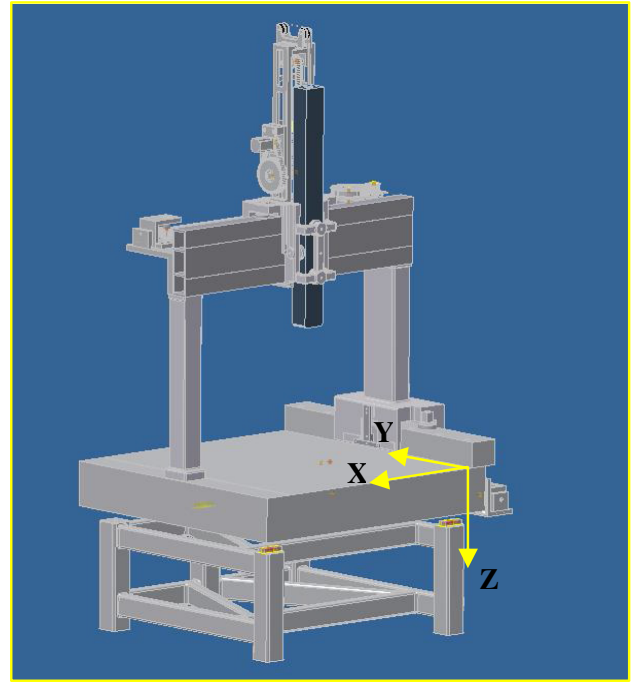

Figure 1. The whole of structure of a moving bridge CMM

Structure elements serve as the backbone of CMM. The machine base, table to support the part to be measured, machine columns, 
slide ways and probe shaft are essential structural elements [1].

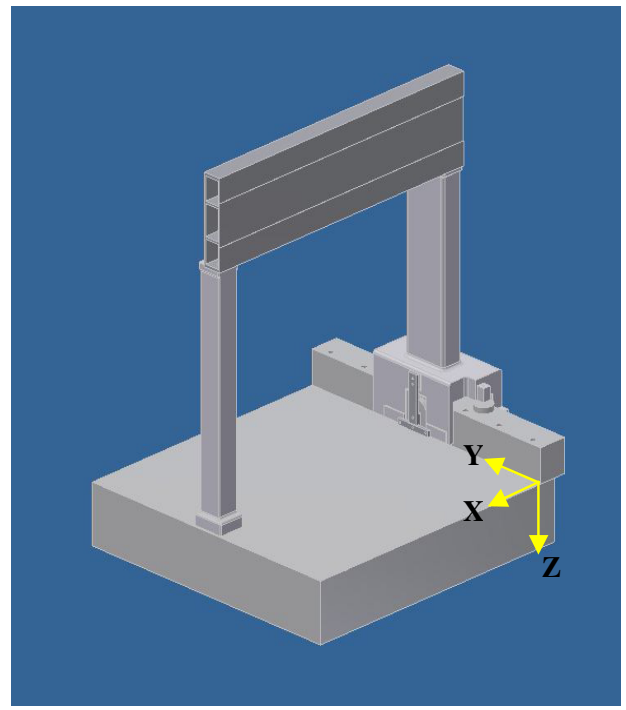

Figure 2. Table, bridge and prismatic joint of a moving bridge $\mathrm{CMM}$

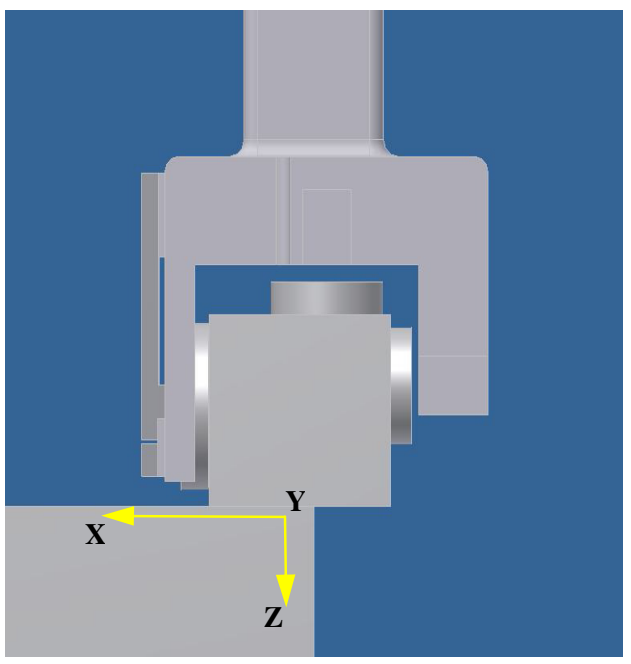

Figure 3. The prismatic joint that moves along $X$ axis of a moving bridge CMM

3. PHYSICAL MODEL OF THE BRIDGE COMPONENT AND THE PRISMATIC JOINT MOVING ALONG THE Y AXIS

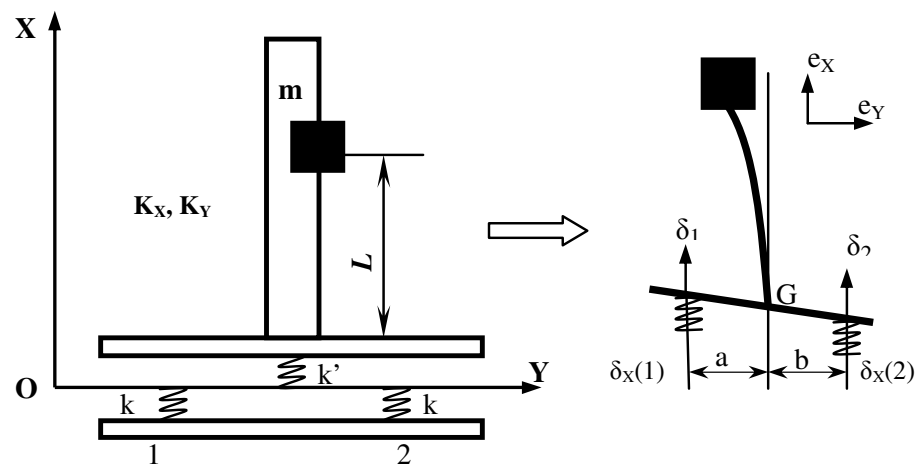

a) Dynamic model of $\delta_{X}(t)$ and $\varepsilon_{Z}(t)$; b) Simplified model of $\delta_{X}(t)$ and $\varepsilon_{Z}(t)$

Figure 4. Top view of the CMM physical model depicts two component errors $\delta_{X}(t)$ and $\varepsilon_{Z}(t)$

To create the physical model of CMM as shown in figure 4 , the bridge is regarded as a mass point $\mathrm{m}$ attached to an elastic beam $\mathrm{L}$. The air bearings, which links the elastic beam to the $\mathrm{X}$ slideway are supposed as three springs. When the probe tip runs at hight speed, accelerates or decelerates, inertia force induced and it makes the bridge, the prismatic joint and the slideways deformed. The translated error along the $\mathrm{X}$ axis $\left(\delta_{X}\right)$ and the rotated error 
about the $\mathrm{Z}$ axis $\left(\varepsilon_{Z}\right)$ due to inertia force are determined as [2]:

$$
\left\{\begin{array}{l}
\delta_{X}(t)=\frac{a \times \delta_{X}(2)+b \times \delta_{X}(1)}{a+b} \\
\varepsilon_{Z}(t)=\frac{\delta_{X}(2)-\delta_{X}(1)}{a+b}
\end{array}\right.
$$

\section{MATHEMATICAL MODEL OF THE BRIDGE COMPONENT AND THE PRISMATIC JOINT MOVING ALONG THE X AXIS -THE DYNAMIC ERRORS OCCURSED ON THE TIP OF THE PROBE DURING FAST MEASURING}

In this case, the influence of acceleration on the accuracy of CMM will be investigated when probe tip run fast along $\mathrm{Y}$ axis. To yield the wanted mathematical model from the physical model of CMM (figure 4), some following assumptions are used:

- The stiffness in $\mathrm{X}$ and $\mathrm{Y}$ direction of the elastic beam are: $\mathrm{K}_{\mathrm{X}}, \mathrm{K}_{\mathrm{Y}}$.

- The distant between the carriage takes Z axis and $\mathrm{Y}$ slideway is $\mathrm{L}$ and the weight of the carriage takes $\mathrm{Z}$ axis is $\mathrm{m}$.

- The air bearings, which links the elastic beam to the $\mathrm{Y}$ slideway are regarded as three springs and their stiffness are $\mathrm{k}$ and k'.

- The errrors of the probe tip in $\mathrm{X}$ and $\mathrm{Y}$ direction are ex and ey, respectively.

The equation of motion of the multi-degree of freedom linear system has the following form [3]:

$$
M \ddot{x}+C \dot{x}+K x=F(t)
$$

Where:

$+\mathrm{M}$ is the inertia matrix

$+\mathrm{C}$ is the damping matrix

$+\mathrm{K}$ is the stiffness matrix

$+\mathrm{F}$ is the external excitation matrix

$+\mathrm{x}$ is the displacement matrix

Application of the Newton's law for the physical model in figure 3 result in the following equations of motion:

In the $\mathrm{Y}$ direction:

$$
m \ddot{e}_{Y}(t)+K_{Y} e_{Y}(t)+K_{Y} \cdot L \varepsilon_{Z}(t)=0
$$

By using the moment equilibrium condition of the bridge about point $G$, the relationship of the $K_{Y}, K, k$ and $k$ stiffness is shown:

$$
K_{Y}=K \frac{a^{2}+b^{2}}{L^{2}} ; K=\frac{2 k \cdot k^{\prime}}{2 k+k^{\prime}} \text { (a) }
$$

To produce the solutions of the differential equation (3), this equation is presented in other form:

$\ddot{e}_{Y}(t)+K \frac{a^{2}+b^{2}}{m L^{2}} e_{Y}(t)=-K \frac{a^{2}+b^{2}}{m L} \varepsilon_{Z}(t)(\mathrm{b})$

The general solution of the homogeneous linear differential equation has to be found:

$$
\ddot{e}_{Y}(t)+K \frac{a^{2}+b^{2}}{m \cdot L^{2}} e_{Y}(t)=0
$$

The characteristic equation of the differential equation (c) has two root, they are:

$$
\lambda_{1}=i \cdot \sqrt{K \frac{a^{2}+b^{2}}{m \cdot L^{2}}} ; \lambda_{2}=-i \cdot \sqrt{K \frac{a^{2}+b^{2}}{m \cdot L^{2}}}
$$


By using Euler's formula, the general solution of the homogeneous linear differential equation (c) is written :

$e_{Y}=C_{1} \cos \left(\sqrt{K \frac{a^{2}+b^{2}}{m \cdot L^{2}}} t\right)+C_{2} \sin \left(\sqrt{K \frac{a^{2}+b^{2}}{m \cdot L^{2}}} t\right)(\mathrm{e})$

To get the solution of the nonhomogeneous linear differential equation (b), we will use the variation of constants method with some assumptions:

$-\mathrm{C}_{1}, \mathrm{C}_{2}$ are functions

$-\mathrm{C}_{1}, \mathrm{C}_{2}$ are chosen:

$C_{1}^{\prime} \cos \left(\sqrt{K \frac{a^{2}+b^{2}}{m \cdot L^{2}}} t\right)+C_{2}^{\prime} \sin \left(\sqrt{K \frac{a^{2}+b^{2}}{m \cdot L^{2}}} t\right)=0$ (f)

Hence, the $C_{1}^{\prime} ; C_{2}^{\prime}$ are determined by the set of following differential equations:

$$
\left\{\begin{array}{l}
\left.C_{1} \cos \sqrt{K \frac{a^{2}+b^{2}}{m L^{2}}} t\right)+C_{2} \sin \left(\sqrt{K \frac{a^{2}+b^{2}}{m L^{2}}} t\right)=0 \\
\left.-C_{1} \sqrt{K \frac{a^{2}+b^{2}}{m L^{2}}} \cdot \sin \left(\sqrt{K \frac{a^{2}+b^{2}}{m L^{2}}} t\right)+C_{2} \sqrt{K \frac{a^{2}+b^{2}}{m L^{2}}} \cos \sqrt{K \frac{a^{2}+b^{2}}{m L^{2}}} t\right)=0
\end{array}\right.
$$

(g)

The $\mathrm{C}_{1}, \mathrm{C}_{2}$ constants are found out from set of equations $(\mathrm{g})$ :

$$
\left\{\begin{array}{l}
C_{1}=-\frac{K \frac{a^{2}+b^{2}}{m L} \varepsilon_{Z}(t)}{K \frac{a^{2}+b^{2}}{m \cdot L^{2}}} \cos \left(\sqrt{K \frac{a^{2}+b^{2}}{m \cdot L^{2}}} t\right)+H_{1} \\
C_{2}=\frac{K \frac{a^{2}+b^{2}}{m L} \varepsilon_{Z}(t)}{K \frac{a^{2}+b^{2}}{m \cdot L^{2}}} \sin \left(\sqrt{K \frac{a^{2}+b^{2}}{m \cdot L^{2}}} t\right)+H_{2}
\end{array}\right.
$$

(h)

The $\mathrm{H}_{1}, \mathrm{H}_{2}$ in the above expression are two arbitrary constants. To simplify, the $\mathrm{H}_{1}, \mathrm{H}_{2}$ are taken $\mathrm{H}_{1}=\mathrm{H}_{2}=0$. The $\mathrm{e}_{\mathrm{Y}}$ error which occurs in the $\mathrm{Y}$ direction in fast probing is the solution of the differential equation (3) and it is presented by the following form:

$$
e_{Y}=-L \varepsilon_{Z}(t) \cdot \cos 2 \cdot\left(\sqrt{K \frac{a^{2}+b^{2}}{m \cdot L^{2}}}\right) \cdot t(4)
$$

The natural frequency in the $\mathrm{X}$ direction:

$$
\omega_{Y}=\sqrt{\frac{K\left(a^{2}+b^{2}\right)}{m \cdot L^{2}}}
$$

The $e_{Y}$ error on the probe tip in the $Y$ direction in fast measuring is simulated by MatLab software:

$$
\begin{aligned}
& \text { function } \mathrm{d}=\mathrm{ptvp}(\mathrm{t}, \mathrm{ey}) \\
& \mathrm{F} 0=100 ; \mathrm{K}=60000 ; \mathrm{m}=66.44 ; \mathrm{a}=230 \\
& \mathrm{~b}=230 ; \mathrm{L}=500 ; \mathrm{t} 1=1.0 ; \mathrm{t} 2=5 ; \\
& \mathrm{w} 0=\operatorname{sqrt}\left(\mathrm{K}^{*}\left(\mathrm{a}^{\wedge} 2+\mathrm{b}^{\wedge} 2\right) /\left(\mathrm{m}^{*} \mathrm{~L}^{\wedge} 2\right)\right) \\
& \text { if } \mathrm{t}>=\mathrm{t} 1 \& \mathrm{t}<=\mathrm{t} 2, \mathrm{~F}=\mathrm{F} 0 ; \text { else } \mathrm{F}=0 ; \text { end } \\
& \mathrm{d}=\left[\mathrm{ey}(2) ;\left(-\mathrm{ey}(1)^{*} \mathrm{w}^{\wedge} 2\right)+\mathrm{F} / \mathrm{m}\right]
\end{aligned}
$$

$$
\%
$$

clear all;

ey0 $=[0 ; 0] ;$ ts $=\left[\begin{array}{ll}0 & 5\end{array}\right]$;

[t,ey]=ode45('ptvp',ts,ey0);

figure;plot(t,ey(:,1));

title('sai so Ey khi thuc hien do nhanh'); grid on 


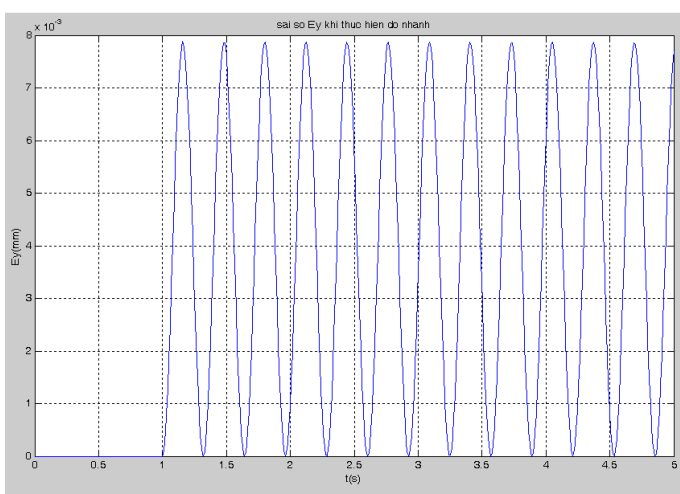

Figure 5. The $\mathrm{e}_{\mathrm{Y}}$ error on the probe tip in fast measuring has been simulated by MatLab.

In the $\mathrm{X}$ direction:

$$
m \ddot{e}_{X}(t)+K_{X} \cdot e_{X}(t)+K_{X} \delta_{X}(t)=0
$$

The $\mathrm{K}_{\mathrm{X}}$ stiffness has relationship with $\mathrm{K}, \mathrm{k}$ and $k^{\prime}$. This relationship is defined by force equilibrium condition in the $\mathrm{Y}$ direction:

$$
K_{X}=K ; \quad K=\frac{2 k \cdot k^{\prime}}{2 k+k^{\prime}}
$$

The differential equation (6) is written in other form:

$$
\ddot{e}_{X}(t)+\frac{K_{X}}{m} \cdot e_{X}(t)=-\frac{K_{X}}{m} \delta_{X}(t)
$$

The order to find out the solution of the differential equation (6) is similar to the way to get the solution of the differential equation (3). The $e_{X}$ error on the probe tip in fast measuring is the solution of the differential equation (6):

$e_{X}=-\frac{a \delta_{X}(2)+b \delta_{X}(1)}{a+b} \cdot \cos 2\left(\sqrt{\frac{K}{m}}\right) \cdot t$

The natural frequency in the $\mathrm{X}$ direction:

$$
\omega_{X}=\sqrt{\frac{K}{m}}
$$

The $\mathrm{e}_{\mathrm{X}}$ error on the probe tip in $\mathrm{X}$ direction is simulated by MatLab software:

function $\mathrm{d}=\mathrm{ptvp}(\mathrm{t}, \mathrm{ex})$

$\mathrm{F} 0=100 ; \mathrm{K}=60000 ; \mathrm{m}=66.44 ; \mathrm{a}=230$;

$\mathrm{b}=230 ; \mathrm{t} 1=1.0 ; \mathrm{t} 2=5$

$\mathrm{w} 0=\operatorname{sqrt}(\mathrm{K} / \mathrm{m})$;

if $\mathrm{t}>=\mathrm{t} 1 \& \mathrm{t}<=\mathrm{t} 2, \mathrm{~F}=\mathrm{F} 0$; else $\mathrm{F}=0$; end

$\mathrm{d}=\left[\operatorname{ex}(2) ;\left(-\operatorname{ex}(1)^{*} \mathrm{w} 0^{\wedge} 2\right)+\mathrm{F} / \mathrm{m}\right]$

$\%$

clear all;

$\operatorname{ex} 0=[0 ; 0] ; \operatorname{ts}=\left[\begin{array}{ll}0 & 10\end{array}\right]$

$[\mathrm{t}, \mathrm{ex}]=\mathrm{ode} 45($ 'ptvp',ts,ex0);

figure; $\operatorname{plot}(\mathrm{t}, \mathrm{ex}(:, 1))$;

title('sai so Ex khi thuc hien do nhanh'); grid on

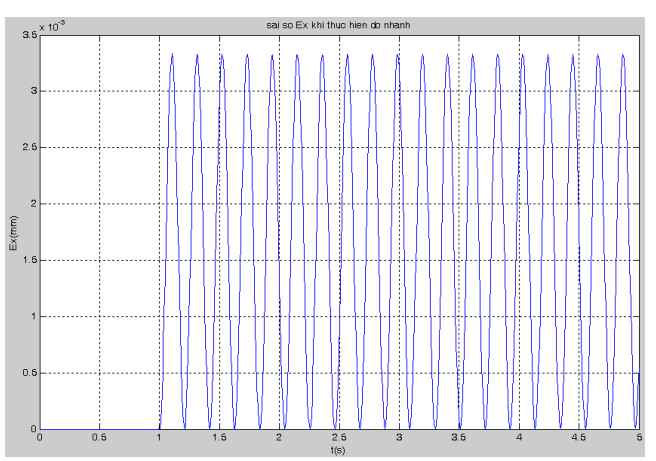

Figure 6. The eX error on the probe tip in fast measuring has been simulated by MatLab.

5. THE EXPERIMENT CONFIRMS THE DYNAMIC ERRORS INDUCED BY ACCELERATION DURING FAST PROBING

To confirm the dynamic errors which caused by acceleration in fast measuring, a 
experiment has been carried out with the CMM made in Viet Nam at the National Key Lab of Digital Control and System Engineering (DCSELAB)

5.1 To make preparations for the experiment

a. The moving bridge CMM made in Viet Nam

b. The length of the end measure is 100 $\mathrm{mm}$, it has been taken from the gage block comparator:

Code: No 516-507

Set: $\quad$ No BM1-46/2-1

Grade: $\quad 1$

Serial: $\quad$ No 983762

c. The probe tip with the radius $1 \mathrm{~mm}$

d. The end measure is put on the table and then fastened by bolt and nut. The end measure is placed so that its length is parallel with the $\mathrm{Y}$ axis (as shown in figure 7).

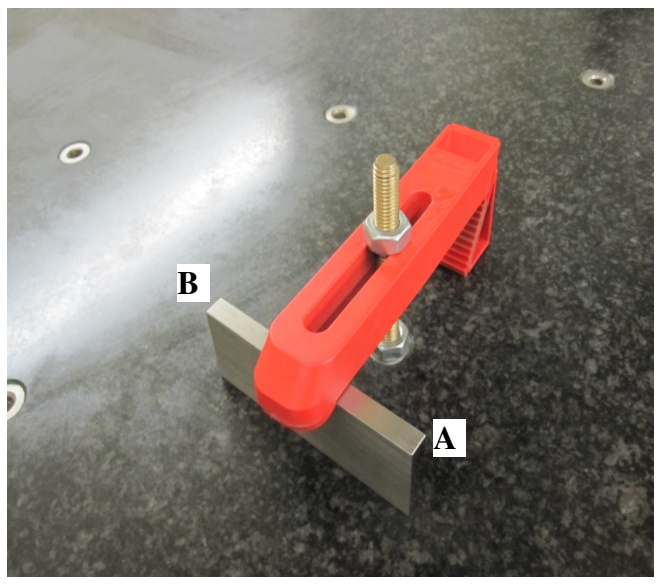

Figure 7. Place and fasten the end measure

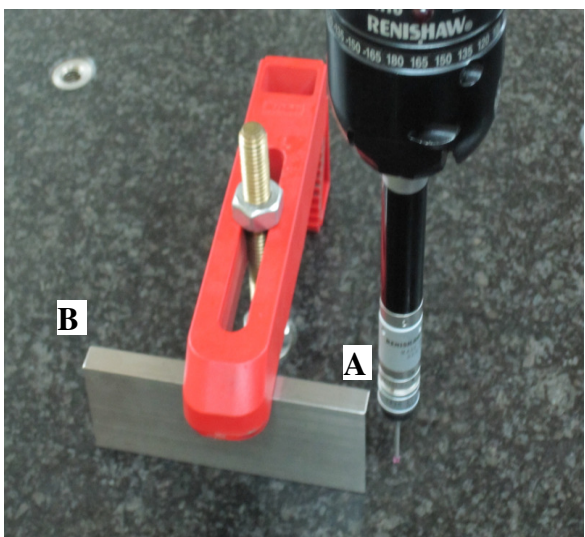

Figure 8. Performing the experiment

\subsection{Perform the experiment}

In the experiment some factors are taken as following:

- The traveling distance of the probe tip: $20 \mathrm{~mm}$

- The approach distance to the surface: $5 \mathrm{~mm}$

- The position of the probe tip in the $X$ direction: $500 \mathrm{~mm} \pm 2 \mathrm{~mm}$

\subsection{The results of the experiment}

a. When measuring with the little changing measuring speed: the speed of the approach to the surface is taken $1 \mathrm{~mm} / \mathrm{s}$; the traveling speed is chosen less than $8 \mathrm{~mm} / \mathrm{s}$, the measuring results are accurate. The length of the end measure is:

$$
l=102 \pm 0.003 \mathrm{~mm}
$$

b. When the traveling speed is taken $10 \mathrm{~mm} / \mathrm{s}$ and the speed of the approach to the surface is chosen $1 \mathrm{~mm} / \mathrm{s}$, the length of the length bar is measured in the $\mathrm{Y}$ direction as results in following table: 
Table 1.

\begin{tabular}{|c|c|c|c|c|}
\hline Point & $\begin{array}{c}\text { Side } \mathrm{A}\left(\mathrm{Y}_{\mathrm{A}}\right) \\
(\mathrm{mm})\end{array}$ & $\begin{array}{c}\text { Side B }\left(\mathrm{Y}_{\mathrm{B}}\right) \\
(\mathrm{mm})\end{array}$ & $\begin{array}{c}\mathrm{Z} \\
(\mathrm{m})\end{array}$ & $\begin{array}{c}\text { Errors in the } \mathrm{Y} \\
\text { direction } \\
(\mu \mathrm{m})\end{array}$ \\
\hline 1 & 1.894 & 103.918 & 0 & 24 \\
\hline 2 & 1.893 & 103.917 & 1 & 24 \\
\hline 3 & 1.892 & 103.917 & 2 & 25 \\
\hline 4 & 1.899 & 103.915 & 3 & 16 \\
\hline 5 & 1.901 & 103.915 & -2 & 14 \\
\hline & $\bar{Y}_{A}=1.8958$ & $\bar{Y}_{B}=103.9164$ & & 20.6 \\
\hline
\end{tabular}

c. The length of the length bar is measured

chosen $60 \mathrm{~mm} / \mathrm{s}$ and the speed of the approach in the $\mathrm{Y}$ direction when the traveling speed is to the surface is $1 \mathrm{~mm} / \mathrm{s}$

Table 2.

\begin{tabular}{|c|c|c|c|c|}
\hline point & $\begin{array}{c}\text { Side A }\left(\mathrm{Y}_{\mathrm{A}}\right) \\
(\mathrm{mm})\end{array}$ & $\begin{array}{c}\text { Side B }\left(\mathrm{Y}_{\mathrm{B}}\right) \\
(\mathrm{mm})\end{array}$ & $\begin{array}{c}\mathrm{Z} \\
(\mathrm{mm})\end{array}$ & $\begin{array}{c}\text { Errors in the } \\
\text { direction } \\
(\mu \mathrm{m})\end{array}$ \\
\hline 1 & 1.800 & 103.893 & -2 & 93 \\
\hline 2 & 1.805 & 103.888 & -1 & 83 \\
\hline 3 & 1.802 & 103.889 & 0 & 87 \\
\hline 4 & 1.803 & 103.920 & 1 & 117 \\
\hline 5 & 1.809 & 103.919 & 2 & 110 \\
\hline & $\bar{Y}_{A}=1.8038$ & $\bar{Y}_{B}=103.9018$ & & 102.098 \\
\hline
\end{tabular}

\section{CONCLUSION}

The influence of acceleration on the accuracy of a CMM (made in VietNam) in fast measuring has been investigated. The results of theoretic and practical research points out that the dynamic errors are always to be on CMMs during probing, especially in fast measuring. The dynamic errors affect and reduce the accuracy of the measuring results. Therefore, it is necessary to find out the way to compensate for these errors in order to keep up the CMMs accuracy in fast measuring.

\section{Trang 66}




\title{
ẢNH HƯởNG CỦA YẾU TỐ GIA TỐC ĐẾN Độ CHÍNH XÁC CỦA MÁY ĐO TọA ĐỘ KHI ĐO NHANH
}

\author{
Thái Thị Thu Hà , Phạm Hồng Thanh \\ Trường Đại học Bách Khoa, ĐHQG-HCM
}

TÓM TÁT: Bài báo trình bày một cách tiếp cận theo lý thuyết và thực tế để xác định thành phần sai số động lực học do gia tốc gây ra trên máy đo tọa độ khi đo nhanh. Để đơn giản, nghiên cứu chỉ trình bày mô hìn vật lý và mô hình toán học của bộ phận cầu và khớp truợt dọc theo truc X của máy đo tọa độ. Nghiên cứu cho thấy rằng, chắc chắn có sai số động lục học khi có gia tốc. Điều này được chưng minh nhờ việc mô phỏng sai số ở đầu dò bằng phần mềm Matlab và bằng các kết quả thực nghiệm nhận được khi đo một căn mẫu. Sai số động lực học sẽ làm giảm độ chính xác của máy đo tọa độ vì vậy cần phải xây dựng một phần mềm bù sai số để đảm bảo độ chính xác của kết quả đo.

Tù khóa: Fast measuring, Fast probing, CMMS, Accuracy, Velocity, Dynamic error...

\section{REFERENCES}

[1]. P.C Jain, R.P. Singhal. Dimentional Metrology: Coordinate measurements. ISBN No 81-7556-277-3, A Pragati's publication (2001).

[2]. Wei Jinwen, Chen Yanling, The geometric dynamic errors of CMMs in fast scanning-probing, Measurement, 44, 3, 511-517 (March 2011).

[3]. J.M. Krodkiewski, Mechanical Vibration. The University of Melbourne (2008).

[4]. W. van Vliet, Development of a Fast Mechanical Probe for Coordinate Measuring Machine, ISBN 90-386-
01689, PhD thesis, Eindhoven University of Technology (1996).

[5]. David Flak, Measurement Good Practice Guide No.43, ISSN 1368-6650, National Physical Laboratory Queens Road, Teddington, Middlesex, United Kingdom, TW11 0LW (2001).

[6]. W. Onno Pril, Development of High Precision Mechanical Probes for Coordinate Measuring Machine, $\mathrm{PhD}$ thesis, Eindhoven University of Technology (2002).

[7]. W.C.Young, Roark's Formulas for Stress and Strains, ISBN 0 -07-1003738, McGraw-Hill (1989). 
[8]. Butler C, An investigation into the performance of probes on coordinate measuring machine, Industrial Metrology 2 (1991).

[9]. Tyler Estler W. et al, Practical aspect of touch-trigger probe error compensation, Precision Engineering 21 (1997).

[10]. Woz'niak A., Dobosz M., Research on hysteresis of triggering probes applied in coordinate measuring machines, Metrology and Measurement Systerms, 12, 4 (2005).

[11]. Renishaw, Probing systerms for coordinate measuring machines, United Kingdom (1996).
[12]. W. G. Weekers and PP. H. J. Schellekens. Compensation for Dynamic Errors of Coordinate Measuring Machines. Measurement, 20, 3 (1997).

[13]. X.M.Targ, Giáo trình giản yếu co hoc lý thuyết (1979).

[14]. Thái Thị Thu Hà, Thiết kế chế tạo máy đo tọa độ, Đề tài KC05, DCSELAB (2010).

[15]. Johnson. K.L, Contact mechanics, Cambridge University Press, New York (1985).

[16]. Tabor. D. The hardness of metals, Oxford University Press, London (1951). 